\title{
Umbilical vessel wall fatty acids after normal and retarded fetal growth
}

\author{
C V Felton, T C Chang, D Crook, M Marsh, S C Robson, J A D Spencer
}

\begin{abstract}
In a prospective observational study, the fatty acid content of human umbilical artery and vein wall phospholipids was determined in fetuses classified according to their change in abdominal circumference during the third trimester. Three groups were identified: appropriate for gestational age (AGA; 24 infants) and small for gestational age (SGA; 38 infants) with normal antenatal growth rate, and SGA with fetal growth retardation (22 infants). The venous linoleic acid (18:2 $\omega 6)$ content (expressed as a percentage of the total fatty acids identified) was greater in growth retarded SGA fetuses $(3.5(0.6) \%)$ than in SGA fetuses with a normal growth rate $(3.1(0.5) \%)$ and AGA fetuses (3.0 $(0.5) \%$, whereas the venous contents of eicosatrienoic $(20: 3 \omega 6)$ and docosahexaenoic acid (22:6 $\omega 3)$ were lower. In growth retarded SGA fetuses, the venous and arterial $20: 3 \omega 6$ content correlated with the change in abdominal circumference. In SGA fetuses with a normal growth rate, lower contents of arterial 18:2 $\omega 6$ and $22: 6 \omega 3$ were associated with a smaller change in abdominal circumference and birth weight. Different metabolic derangements appear to underly normal and subnormal growth rate in SGA fetuses, suggesting that different strategies of dietary intervention may be required to aid fetal growth and reduce the sequelae of fetal growth retardation. (Arch Dis Child 1994; 70: F36-F39)
\end{abstract}

The umbilical artery and vein walls contain fatty acids derived from the blood flowing through them. Differences in their fatty acid composition reflect nutritional supply and use during pregnancy. ${ }^{1}$ A study of fatty acids in cord blood from appropriate for gestational age (AGA), small for gestational age (SGA), and preterm SGA fetuses showed a higher linoleic

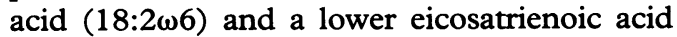
$(20: 3 \omega 6)$ content in the SGA fetuses. ${ }^{2}$ This study was limited, however, because birth weight was used to define nutritional status. Birth weight is a poor predictor of perinatal outcome associated with fetal growth retardation as some SGA infants are preceded by a normal growth rate, as judged by ultrasound, and are clinically well nourished. ${ }^{3-5}$ Serial ultrasound measurements of abdominal circumference have been shown to predict neonatal wasting associated with fetal growth retardation. ${ }^{6}$

Differences in the placental supply of essential fatty acids may influence fetal growth.
To investigate this, we measured the umbilical artery and vein wall phospholipid fatty acid contents in AGA and SGA infants who had normal and subnormal growth rates.

\section{Methods}

\section{SUBJECTS}

Eighty four women were recruited after referral to the ultrasound department because of a suspected small fetus during the third trimester of pregnancy. In 60 subjects a SGA fetus was confirmed by an abdominal circumference less than the 10th centile for gestational age. ${ }^{7}$ The remaining 24 fetuses had an abdominal circumference larger than the 10th centile for gestational age and were used as AGA controls. All fetuses were subsequently scanned at intervals of one to two weeks until delivery. All women had at least three scans and delivered after 36 weeks' gestation. All were certain of the date of their last menstrual period and had fetal size confirmed as appropriate by biparietal diameter and femur length at the 18-20 week anomaly scan. Fetal growth rate was quantified by calculating the change in SD score of abdominal circumference between the first scan after recruitment and the last before delivery. This methodology has been described in detail and been shown to identify neonatal morphometry consistent with fetal growth retardation. ${ }^{6}$ Individual SD scores were calculated as the measured abdominal circumference minus the mean abdominal circumference from a reference population at the same gestational age, divided by the SD of abdominal circumference from the reference population. We used our own reference standards. ${ }^{8}$ A change in SD greater than -1.5 was used to classify fetal growth retardation. Informed consent was obtained and the study was approved by the hospital ethics committee.

ANALYSIS OF UMBILICAL ARTERY AND VEIN FATTY ACIDS

Lengths of umbilical cord $(5-10 \mathrm{~cm})$ were stored at $-20^{\circ} \mathrm{C}$ for up to six months. Before analysis a $1 \mathrm{~cm}$ length of umbilical vein and artery was dissected out, cut lengthwise, and rinsed in ice cold isotonic saline. To extract the lipids, the vessels were homogenised in redistilled chloroform/methanol $(2: 1, \mathrm{v} / \mathrm{v})$ containing $0.01 \% \mathrm{w} / \mathrm{v}$ butylated hydroxytoluene as antioxidant. After a Folch wash ${ }^{9}$ the phospholipid fraction was separated by thin layer chromatography. Phospholipid fatty acids were transmethylated using $0.5 \mathrm{M}$ sodium methoxide in dry methanol $\left(50^{\circ} \mathrm{C}\right.$ for $10 \mathrm{~min}$ - 
Table 1 Demographic and other details of subjects

\begin{tabular}{|c|c|c|c|}
\hline & $\begin{array}{l}A G A \\
(n=24)\end{array}$ & $\begin{array}{l}S G A \\
\text { normal growth rate } \\
(n=38)\end{array}$ & $\begin{array}{l}S G A \\
\text { growth retarded } \\
(n=22)\end{array}$ \\
\hline $\begin{array}{l}\text { No }(\%) \text { primigravidae } \\
\text { No (\%) smokers }\end{array}$ & $\begin{array}{r}12(50) \\
9(38)\end{array}$ & $\begin{array}{r}20(53) \\
5(13)\end{array}$ & $\begin{array}{l}12(55) \\
10(45)^{\star}\end{array}$ \\
\hline Birth weight (g) & $3570(3200-4200)$ & $2569(1701-3120)$ & $2277(1360-2900)$ \\
\hline $\begin{array}{l}\text { Gestational age at } \\
\text { delivery (days) }\end{array}$ & $274(254-289)$ & $272(257-292)$ & $269(253-290)$ \\
\hline $\begin{array}{l}\text { No }(\%) \text { caesarean sections } \\
\text { for fetal distress } \\
\text { Admissions to NICU† } \\
\text { Ponderal index } \\
\text { MAC/HC ratio } † \\
\text { Subscapular skinfold } \\
\text { Triceps skinfold }\end{array}$ & $\begin{array}{l}3(13) \\
0 \\
2 \cdot 60(2 \cdot 38-2 \cdot 98) \\
0 \cdot 31(0 \cdot 28-0 \cdot 35) \\
4 \cdot 6(2 \cdot 9-6 \cdot 1) \\
4 \cdot 7(3 \cdot 1-6 \cdot 2)\end{array}$ & $\begin{array}{l}4(11) \\
1(3) \\
2 \cdot 45(2 \cdot 13-3 \cdot 42) \\
0 \cdot 28(0 \cdot 22-0 \cdot 33) \\
3 \cdot 1(2 \cdot 2-4 \cdot 4) \\
3 \cdot 1(2 \cdot 2-4 \cdot 4)\end{array}$ & $\begin{array}{l}3(14) \\
5(23)^{\star} \ddagger \\
2 \cdot 28(1 \cdot 90-2 \cdot 93)^{\star} \ddagger \\
0 \cdot 26(0 \cdot 23-0 \cdot 30)^{\star} \ddagger \\
2 \cdot 7(2 \cdot 0-4 \cdot 3)^{\star} \ddagger \\
2 \cdot 7(1 \cdot 8-4 \cdot 2)^{\star} \ddagger\end{array}$ \\
\hline
\end{tabular}

${ }^{\star} \mathrm{p}<0.05$ versus SGA fetuses with normal growth rate

+ NICU = neonatal intensive care unit; $M A C / H C=$ mid-arm circumference/head circumference. $\dashv \mathrm{TICU}=$ neonatal intensive $\mathrm{Car}$

$\neq \mathrm{p}<0.05$ versus AGA fetuses.
Categorical variables tested by Fisher's exact test or $\chi^{2}$ test where appropriate.

Continuous variables assessed by Mann-Whitney U test. Values are median (range)

utes). After extraction of the methyl esters into hexane, their fatty acid composition was determined using a PU4400 gas liquid chromatograph (Phillips Scientific, Cambridge) fitted with a $1.5 \mathrm{~m} \times 4.0 \mathrm{~mm}$ ID glass column packed with $10 \%$ SP2330 on $100 / 120$ Chromosorb (Supelchem, Essex). Retention times were compared with those of high purity $(>99 \%)$ standards (Sigma Chemical, Poole, Dorset). Peaks were analysed using an IBM PS/2 microcomputer and Nelson 2600 software (Perkin-Elmer Nelson Systems, Buckinghamshire). Precision was assessed using replicate aliquots of serum extracts. At compositions of $1 \cdot 9,7 \cdot 5$, and $36 \cdot 7 \%$ fatty acid the coefficients of variation were $3.9,0.9$, and $0.8 \%$ respectively. Individual fatty acids were expressed as a percentage of the total fatty acids identified.

\section{STATISTICAL ANALYSIS}

Fatty acid data were analysed using Student's paired (umbilical artery and vein comparisons) and unpaired (fetal groups) $t$ test (two tailed). Similar results were obtained when the data were analysed using non-parametric tests. Linear regression and Pearson's correlation coefficients were used to examine relations between the fatty acid content and fetal growth in the SGA groups. Demographic data were analysed using the Mann-Whitney $U$ test and either Fisher's exact test or the $\chi^{2}$ test.

\section{Results}

All 60 SGA fetuses had a birth weight less than the 10th centile for gestational age, whereas all 24 AGA fetuses showed normal fetal growth and had a birth weight greater than the 10th centile for gestational age. Of the SGA fetuses, 22 showed a change in SD score of abdominal circumference greater than -1.5 and were considered to be growth retarded. Thirty eight had a normal growth rate. There was no significant difference in mean gestational age at delivery between the three groups (table 1). The median birth weight was significantly lower in the growth retarded SGA group (1360-2900 g) than for SGA fetuses with normal growth rate $(1701-3120 \mathrm{~g} ; \mathrm{p}<0.05)$ and AGA controls $(3200-4200 \mathrm{~g} ; \mathrm{p}<0.05)$. The prevalence of maternal smoking was similar in the growth retarded SGA (45\%) and AGA $(38 \%)$ groups, but was significantly lower in the SGA group with normal growth rate $(13 \%$; $\mathrm{p}<0.05)$ compared with the growth retarded SGA group. In the growth retarded SGA group, the ponderal index, subscapular skinfold, triceps skinfold, and mid-arm circumference/head circumference ratio were significantly lower than the SGA group with a normal growth rate $(p<0.05)$ and AGA controls $(p<0.05)$.

In all three fetal groups, the venous wall content of series 6 polyunsaturated fatty acids was higher and the content of monounsaturated fatty acids and docosahexaenoic acid $(22: 6 \omega 3)$ were lower than in the arterial wall

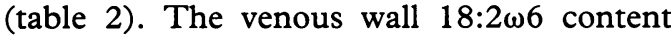
was greater $(3.5(0.6) \%)$ in the growth retarded SGA group than in the SGA group with normal growth rate $(3.1 \quad(0.5) \%$; $\mathrm{p}<0.05)$ and AGA $(3.0(0.5) \% ; \mathrm{p}<0.01)$ group, and also in the SGA group with normal growth rate compared with the AGA $(p<0.01)$ group. No between group difference in the arterial wall content of $18: 2 \omega 6$ was observed. In growth retarded SGA fetuses, the venous and arterial wall contents of $20: 3 \omega 6$ $(2.3(0.6)$ and $1.5(0.3) \%$ respectively) were lower than in the SGA fetuses with normal growth rate $(2.6(0.4) \% ; \mathrm{p}<0.01$ and 1.9 $(0.3) \% ; \mathrm{p}<0.01)$ and the AGA fetuses $(2.6$ $(0.5) \% ; \mathrm{p}<0.05$ and $2.0(2.0) \% ; \mathrm{p}<0.001)$ (table 2).

Table 2 Comparison of fatty acid content of umbilical artery and vein wall phospholipids. Values are mean (SD) percentages

\begin{tabular}{|c|c|c|c|c|c|c|c|}
\hline \multirow{2}{*}{\multicolumn{2}{|c|}{ Fatty acid }} & \multicolumn{3}{|c|}{ Umbilical artery } & \multicolumn{3}{|c|}{ Umbilical vein } \\
\hline & & $\begin{array}{l}A G A \\
(n=24)\end{array}$ & $\begin{array}{l}\text { SGA } \\
\text { normal growth rate } \\
(n=38)\end{array}$ & $\begin{array}{l}S G A \\
\text { growth retarded } \\
(n=22)\end{array}$ & $\begin{array}{l}A G A \\
(n=24)\end{array}$ & $\begin{array}{l}S G A \\
\text { normal growth rate } \\
(n=38)\end{array}$ & $\begin{array}{l}\text { SGA } \\
\text { growth retarded } \\
(n=22)\end{array}$ \\
\hline $\begin{array}{l}14: 0 \\
16: 0 \\
16: 1 \omega 7 \\
18: 0 \\
18: 1 \omega 9 \\
18: 2 \omega 6 \\
20: 1 \omega 9 \\
20: 3 \omega 6 \\
20: 4 \omega 6 \\
22: 4 \omega 6 \\
24: 1 \omega 9 \\
22: 6 \omega 3 \\
\text { Other }\end{array}$ & $\begin{array}{l}\text { (myristic) } \\
\text { (palmitic) } \\
\text { (palmitoleic) } \\
\text { (stearic) } \\
\text { (oleic) } \\
\text { (linoleic) } \\
\text { (eicosenoic) } \\
\text { (eicosatrienoic) } \\
\text { (arachidonic) } \\
\text { (docosatetraenoic) } \\
\text { (tetracosenoic) } \\
\text { (docosahexaenoic) }\end{array}$ & $\begin{array}{r}1.1(0.2) \\
20.5(1.0) \\
3.0(0.7) \\
20.8(0.9) \\
18.3(2.8) \\
2.2(2.2) \\
1.0(0.3) \\
2.0(2.0) \\
14.7(1.9) \\
3.7(0.8) \\
3.9(0.9) \\
6.9(1.5) \\
1.9(1.6)\end{array}$ & $\begin{array}{r}1.2(0.3) \\
20.9(2.0) \\
3.2(0.9) \\
20.5(0.9) \\
18.5(2.8) \\
2.2(0.4) \\
1.0(0.2) \\
1.9(0.3) \\
15.0(2.1) \\
3.5(0.8) \\
3.9(0.8) \\
6.9(1.2) \\
1.5(0.4)\end{array}$ & $\begin{array}{l}1 \cdot 2(03) \\
20 \cdot 5(2 \cdot 2) \\
3 \cdot 2(0 \cdot 5) \\
20 \cdot 8(1 \cdot 4) \\
19 \cdot 5(2 \cdot 4) \\
2 \cdot 1(0 \cdot 4) \\
1 \cdot 1(0 \cdot 3) \\
1 \cdot 5(0 \cdot 3)^{\star \star \star}+\dagger \\
14 \cdot 3(2 \cdot 5) \\
3 \cdot 4(0 \cdot 7) \\
4 \cdot 1(1 \cdot 1) \\
6 \cdot 4(1 \cdot 2) \\
2 \cdot 1(1 \cdot 4)\end{array}$ & $\begin{array}{r}0.9(0.2) \\
22.2(1.3) \\
2.0(0.5) \\
18.8(1.1) \\
13.7(1.5) \\
3.0(0.5) \\
0.5(0.2) \\
2.6(0.5) \\
19.1(1.5) \\
5.9(1.1) \\
3.1(1.1) \\
6.5(1.1) \\
1.5(0.4)\end{array}$ & 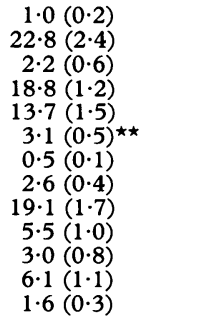 & $\begin{array}{l}0.9(0 \cdot 3) \\
22 \cdot 7(2 \cdot 9) \\
2 \cdot 3(0 \cdot 8) \\
19 \cdot 0(1 \cdot 1) \\
14 \cdot 1(1 \cdot 6) \\
3.5(0 \cdot 6)^{\star \star} \dagger \\
0.6(0 \cdot 1) \\
2 \cdot 3(0 \cdot 6)^{\star}+\dagger \\
19 \cdot 2(2 \cdot 3) \\
5 \cdot 4(1 \cdot 2) \\
2.9(0 \cdot 8) \\
5 \cdot 7(1 \cdot 3)^{\star} \\
1 \cdot 7(0 \cdot 3)\end{array}$ \\
\hline
\end{tabular}

${ }^{\star} \mathrm{p}<0.05 v$ control; ${ }^{\star \star} \mathrm{p}<0.01 v$ control; ${ }^{\star \star \star} \mathrm{p}<0.001 v$ control.

$+\mathrm{p}<0.05 \mathrm{SGA}$ growth retarded $v$ SGA normal growth; $\mathrm{Htp}<0.01 v$ SGA growth retarded $v$ SGA normal growth

$\neq$ Trace fatty acids, each representing $<1 \%$ of total. 
Table 3 Correlations between fatty acid content and growth indices in the SGA groups

\begin{tabular}{|c|c|c|c|c|c|c|c|c|}
\hline \multirow[b]{3}{*}{ Growth index } & \multicolumn{8}{|c|}{ Fatty acid } \\
\hline & \multicolumn{2}{|c|}{$18: 2 \omega 6$} & \multicolumn{2}{|l|}{$20: 3 \omega 6$} & \multicolumn{2}{|l|}{$22: 6 \omega 3$} & \multicolumn{2}{|c|}{$20: 3 \omega 6 / 18: 2 \omega 6$ ratio } \\
\hline & Vein & Artery & Vein & Artery & Vein & Artery & Vein & Artery \\
\hline \multicolumn{9}{|c|}{ Growth rate $(\Delta S D$ of $A C)$} \\
\hline Growth retarded & 0.06 & 0.18 & $0.63^{\star \star}$ & $0 \cdot 68^{\star \star \star}$ & 0.34 & $0 \cdot 20$ & $0 \cdot 41$ & $0 \cdot 48^{\star}$ \\
\hline Normal growth & $0 \cdot 20$ & $0.62^{\star \star \star}$ & $0 \cdot 14$ & $0 \cdot 11$ & $0 \cdot 26$ & $0 \cdot 16$ & $0 \cdot 10$ & $0 \cdot 34^{\star}$ \\
\hline \multicolumn{9}{|l|}{ Birth weight } \\
\hline Growth retarded & $0 \cdot 11$ & 0.07 & $0 \cdot 52^{\star}$ & $0.52^{\star}$ & $0 \cdot 60^{\star \star}$ & $0 \cdot 44^{\star}$ & $0 \cdot 46^{\star}$ & 0.41 \\
\hline Normal growth & $0 \cdot 02$ & $0 \cdot 31$ & $0 \cdot 24$ & $0 \cdot 14$ & $0 \cdot 27$ & $0 \cdot 32^{\star}$ & $0 \cdot 13$ & $0 \cdot 15$ \\
\hline \multicolumn{9}{|l|}{ Gestational age } \\
\hline Growth retarded & $0 \cdot 29$ & $0 \cdot 10$ & $0 \cdot 11$ & 0.08 & 0.34 & $0 \cdot 20$ & $0 \cdot 32$ & 0.04 \\
\hline Normal growth & $0 \cdot 11$ & $0 \cdot 20$ & $0 \cdot 11$ & $0 \cdot 18$ & $0 \cdot 22$ & $0 \cdot 37^{\star}$ & $0 \cdot 14$ & $0 \cdot 16$ \\
\hline \multicolumn{9}{|l|}{ Head circumference } \\
\hline Growth retarded & $0 \cdot 15$ & 0.19 & $0 \cdot 44^{\star}$ & 0.35 & $0 \cdot 66^{\star \star}$ & $0.53^{\star}$ & $0.43^{\star}$ & $0 \cdot 56^{\star \star}$ \\
\hline Normal growth & $0 \cdot 02$ & $0 \cdot 14$ & 0.04 & 0.02 & $0 \cdot 12$ & $0 \cdot 18$ & 0.30 & $0 \cdot 19$ \\
\hline
\end{tabular}

Figures refer to Pearson correlation coefficients determined between growth indices and measures of percentage composition. ${ }^{\star} \mathrm{p}<0.05 ;{ }^{\star \star} \mathrm{p}<0.01 ;{ }^{\star \star \star \star} \mathrm{p}<0.001$.

$\triangle \mathrm{SD}$ of $\mathrm{AC}=$ change in $\mathrm{SD}$ score of abdominal circumference.

There was no apparent relation between the venous wall $18: 2 \omega 6$ content and change in abdominal circumference SD score, birth weight, gestation, or head circumference (table 3). In SGA fetuses with normal growth rate, change in abdominal circumference SD score was strongly associated with the arterial wall $18: 2 \omega 6$ content. In the growth retarded SGA group, but not the SGA group with normal growth rate, the venous wall content of $20: 3 \omega 6$ was positively associated with a change in the abdominal circumference SD score, birth weight, and head circumference. In addition, the arterial wall content of $20: 3 \omega 6$ was positively associated with a change in the abdominal circumference SD score and birth weight in growth retarded SGA fetuses.

The arterial wall $20: 3 \omega 6 / 18: 2 \omega 6$ ratio was positively associated with change in abdominal circumference SD score $(r=0 \cdot 48$, slope $=2 \cdot 1$, $\mathrm{p}<0.05)$, birth weight, and head circumference in the growth retarded SGA group, whereas in the SGA group with normal growth rate this ratio was negatively associated with change in abdominal circumference SD score $(r=0 \cdot 34$, slope, slope $=-2 \cdot 1, \mathrm{p}<0 \cdot 05)$.

The venous wall $20: 3 \omega 6 / 18: 6 \omega 6$ ratio was weakly associated with the change in abdominal circumference SD score $(r=0.41$, $\mathrm{p}=0.057$ ), but positively associated with birth weight $(r=0.46, \mathrm{p}<0.05)$ and head circumference $(r=0.43, \mathrm{p}<0.05)$ in growth retarded SGA fetuses. No associations were found with the venous wall ratio in the SGA fetuses with normal growth rate.

The venous and arterial wall 22:6 63 content was positively associated with birth weight and head circumference in the growth retarded SGA group. In SGA fetuses with normal

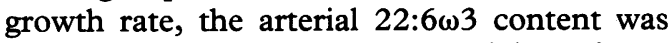
positively associated with birth weight and gestation. No associations were apparent with the venous wall fatty acid content.

\section{Discussion}

This study has shown differences in the umbilical vessel wall fatty acid content of SGA infants with growth retardation compared with SGA and AGA infants with normal fetal growth. This suggests a possible impairment of the placental supply of essential fatty acid derivatives in fetal growth retardation and implies that intervention would necessitate a specific nutritional strategy.

Fetal growth retardation increases the risk of perinatal morbidity and mortality. ${ }^{34}$ Although inadequate maternal nutrition is an important factor in the aetiology of fetal growth retardation worldwide, ${ }^{1011}$ this is not always so. ${ }^{212}$ During pregnancy metabolic adjustments occur that can protect the fetus from dietary inadequacy. ${ }^{13}$ Fetal growth retardation may also be caused by an inadequate supply of nutrients or an inability to use them. ${ }^{14}$ This is especially pertinent in the third trimester of pregnancy where fetal growth is particularly dependent on the supply of long chain polyunsaturated derivatives of essential fatty acids such as arachidonic and docosahexaenoic acid ${ }^{2}$ and prostaglandins. A reduced supply or use of essential fatty acids may be due to impaired placental perfusion, impaired placental processing of parent essential fatty acids, ${ }^{15}$ reduced fetal uptake, or impaired fetal lipolysis. ${ }^{14}$

Differences in fatty acid content within and between groups were apparent in both venous and arterial samples. Concentrations of $\omega 6$ fatty acids were higher in veins than arteries whereas levels of monounsaturates were higher in arteries. This is in agreement with earlier observations from normal pregnancies, ${ }^{1}$ perhaps reflecting preferential use of polyunsaturated fatty acids by the fetus.

The placenta converts linoleic to arachidonic acid using a series of enzyme catalysed desaturation and elongation reactions. ${ }^{16}$ The activity of these enzymes may be compromised by impaired placental development or inhibited by metabolic derangements, such as hypoglycaemia, hypoinsulinaemia, and increased adrenalin and glucocorticoid concentrations, typical of growth retarded SGA fetuses. ${ }^{17}$ An impaired ability of the placenta to supply derivatives of $18: 2 \omega 6$, such as long chain polyunsaturated fatty acids, prostaglandins, and leukotrienes, may influence fetal growth. In the growth retarded SGA group, impaired placental processing of linoleic acid may account for the increased venous content of $18: 2 \omega 6$ and decreased content of 20:3w6. The positive correlation in this group between the venous and arterial wall 
$20: 3 \omega 6$ content and change in abdominal circumference SD score suggests that the impairment may be of graded severity. As the

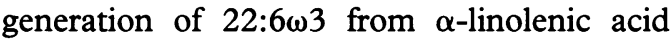
(18:3w3) involves the same enzyme systems, the positive correlation observed in the same group between the venous wall 22:6 63 content and both birth weight and head circumference further supports an impaired and graded placental enzyme activity in this group. As $22: 6 \omega 3$ is an important lipid of neural tissue, ${ }^{18}$ this may influence the incidence of later neurological sequelae in severely growth retarded fetuses. ${ }^{19}$

Eicosatrienoic acid is the first desaturation and elongation product during the placental metabolism of linoleic acid to arachidonic acid $(20: 4 \omega 6)$. Therefore, in umbilical arteries and veins, the ratio of $20: 3 \omega 6 / 18: 2 \omega 6$ may provide an index of placental ability to supply metabolically important derivatives of linoleic acid to the fetus. The arterial ratios of $20: 3 \omega 6 / 18: 2 \omega 6$ in SGA fetuses with growth retardation and normal growth rate were positively and negatively associated with change in abdominal circumference SD score respectively. In growth retarded SGA fetuses this may be attributed to the positive correlation between the arterial wall $20: 3 \omega 6$ content and change in abdominal circumference SD score. In SGA fetuses with normal growth rate a lower content of arterial wall (but not venous wall) 18:2 $\omega 6$ was associated with a reduced change in abdominal circumference SD score and may reflect a marginal deficiency in essential fatty acids in this group. This observation in SGA fetuses with normal growth rate is further supported by an association between lower arterial wall (but not venous wall) 22:6w3 content and lower birth weight.

Maternal essential fatty acids enter the placental circulation along a concentration gradient. ${ }^{20}$ Fetal growth may then be dependent on adequate placental synthesis of long chain derivatives from these essential fatty acids. During the third trimester the major fatty acids that accrue in fetal tissue are long chain derivatives of essential fatty acids, the accumulation of linoleic acid being minimal $(2-3 \%){ }^{21}$ Postnatal tissue is characterised by a substantial accretion of linoleic acid, increases in long chain derivatives not occurring for several weeks. Different metabolic derangements underlying the nutritional status associated with normal growth and growth retardation in SGA fetuses may have marked implications for any potential dietary intervention. Even though the maternal essential fatty acid status may be adequate in cases of growth retardation, direct supplementation of long chain derivatives of essential fatty acids may circumvent any impairment in the placental supply of these fatty acids, thereby assist fetal growth, and prevent some of the associated physiological and neurological sequelae.

We thank the Stanley Foundation for the gift of a gas-liquid chromatograph, and the Heart Disease and Diabetes Research Trust for financial support.

1 Hornstra G, van Houwelingen AC, Simonis M, Gerrard JM. Fatty acid composition of umbilical arteries and veins: possible implications for the fetal EFA-status. Lipids 1989; 24: 511-7.

2 Vilberggson G, Samsoie G, Wennergren M, Karlsson K Essential fatty acids in pregnancies complicated by intrauterine growth retardation. Int $\mathcal{f}$ Gynecol Obstet 1991; 36: 277-86.

3 Patterson RM, Pouliot RN. Neonatal morphometrics and perinatal outcome: who is growth retarded? $A m \mathcal{F}$ Obste Gynecol 1987; 157: 691-3.

4 Villar J, de Onis M, Kestler E, Bolanos E, Cerezo R, Bernedes $\mathrm{H}$. The differential neonatal morbidity of the intra-uterine growth retardation syndrome. $\mathrm{Am} \mathcal{F}$ Obstet Gynecol 1990; 163: 151-7.

5 Chang TC, Robson SC, Boys RJ, Spencer JAD. Prediction of the small for gestational age infant: which ultrasonic of the small for gestational age infant: which ultrasonic

6 Chang TC, Robson SC, Spencer JAD, Gallivan S Identification of fetal growth retardation: comparison of Doppler waveform indices and serial ultrasound measurements of abdominal circumference and fetal weight. Obstet Gynecol 1993; 82: 230-6.

7 Deter RL, Harrist RB, Hadlock FP, Carpenter RJ. Fetal head and abdominal circumferences: II. A critical reevaluation of the relationship to menstrual age. fournal of Clinical Ultrasound 1982; 10: 365-72.

8 Gallivan S, Robson SC, Chang TC, Vaughan J, Spencer JAD. An investigation of fetal growth using serial ultrasound data. Ultrasound in Obstetrics and Gynecology 1993; 3: 109-14.

9 Folch J, Lees M, Sloane-Stanley GH. A simple method for the isolation and purification of total lipids from animal tissues. F Biol Chem 1957; 226: 497-509.

10 Doyle W, Crawford MA, Laurance BM, Drury P. Dietary survey during pregnancy in a low socio-economic group. Human Nutrition: Applied Nutrition 1982; 36A: 95-106.

11 Hornstra G, van der Schouw YT, Bulstra-Ramakers MT, Huisjes HJ. Biochemical EFA status of mothers and their neonates after normal pregnancy. Early Hum Dev 1990; 24: $239-48$.

12 Ministry of Agriculture, Fisheries and Foods. Household food consumption and expenditure. Annual report of the National Food Survey Committee. London: HMSO, 1979.

13 Keirse MJNC. Epidemiology and aetiology of the growth retarded baby. Clin Obstet Gynecol 1984; 11: 415-36.

14 Olegard R, Gustafsson A, Kjellmer I, Victorin L. Nutrition in low birth-weight infants. II. Lipolysis and free fatty acid elimination after intravenous administration of fat emulsion. Acta Pediatr Scand 1975; 64: 745-51.

15 Diaz M, Leal C, Cajal JR, et al. Cord blood lipoproteincholesterol: relationship to birth-weight and gestational age of newborns. Metabolism 1989; 38: 435-8.

16 Zimmerman T, Winkler L, Moller U, Schubert H, Goetze E. Synthesis of arachidonic acid in human placenta in vitro. Biol Neonate 1979; 35: 209-12.

17 Brenner RR. Nutritional and hormonal factors influencing desaturation of essential fatty acids. In: Holman RT, ed. Progress in lipid research. New York: Pergamon Press, 1981: 41-7

18 Crawford MA, Costeloe K, Doyle W, Leighfield MJ, Lennon EA, Meadows N. Potential diagnostic value of the umbilical artery as a definition of neural fatty acid status of the fetus during its growth: the umbilical artery as a diagnostic tool. Biochem Soc Trans 1990; 18: 761-6.

19 Soothill PW, Ajayi RA, Campbell S, et al Relationship between fetal acidemia at cordocentesis and subsequent neurodevelopment. Ultrasound in Obstetrics and Gynecology 1992; 2: 80-3.

20 Thomas CR. Placental transfer of non-esterified fatty acids in normal and diabetic pregnancy. Biol Neonate 1987; 51: 94-101.

21 Clandinin MT, Chappell JE, Heim T. Do low weight infants require nutrition with long chain elongationdesaturation products of essential fatty acids? Prog Lipid Res 1981; 20: 901-4. 